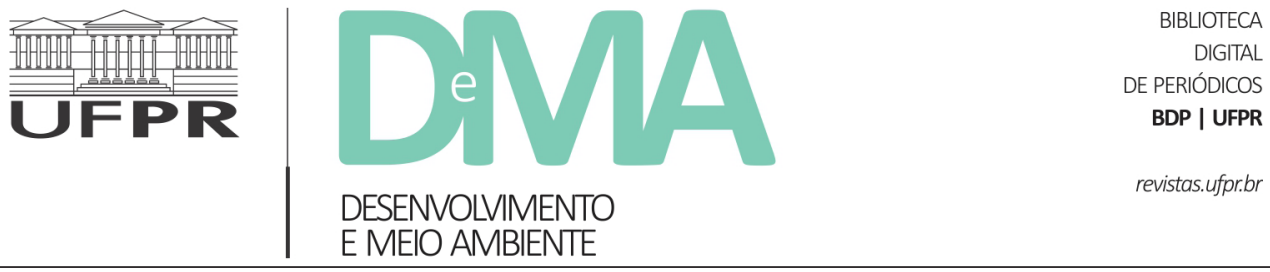

\title{
De naturalista a militante: a trajetória de Rachel Carson
}

\section{From naturalist to militant: the trajectory of Rachel Carson}

\author{
Juliana Capra MAIA ${ }^{1,2^{*}}$, José Luiz de Andrade FRANCO² \\ ${ }^{1}$ Companhia Imobiliária de Brasília (TERRACAP), Brasília, DF, Brasil. \\ ${ }^{2}$ Universidade de Brasília (UNB), Brasília, DF, Brasil. \\ *E-mail de contato: capra.juliana@gmail.com
}

Artigo recebido em 28 de novembro de 2019, versão final aceita em 6 de agosto de 2020, publicado em 23 de março de 2021.

RESUMO: O artigo, síntese de uma pesquisa bibliográfica e documental, reconstitui a trajetória de Rachel Carson, bióloga, escritora e ícone do ambientalismo contemporâneo. Inicialmente, trata de sua vida pessoal, em especial dos fardos e das circunstâncias familiares que condicionaram a sua formação acadêmica e as suas escolhas profissionais. Apresenta, em seguida, a ascensão de Carson como escritora dedicada à divulgação científica, obtida por meio da publicação de uma trilogia a respeito do oceano. Aborda, então, o contexto histórico e as circunstâncias que levaram à elaboração de Primavera Silenciosa, os seus principais argumentos, as estratégias mercadológicas utilizadas para a sua publicação e a repercussão internacional provocada pelo trabalho. Por fim, apresenta as críticas que lhe foram dirigidas.

Palavras-chave: Rachel Carson; Primavera Silenciosa; críticas; ambientalismo contemporâneo; princípios de direito ambiental.

ABSTRACT: This article, a synthesis of bibliographical and documentary research, restores the trajectory of Rachel Carson, biologist, writer, and icon of contemporary environmentalism. Initially, it deals with her personal life, especially with the burdens and familiar circumstances that conditioned her academic formation and her professional choices. Then, it presents the rise of Carson as a writer dedicated to scientific dissemination and the success obtained through a famous trilogy on the ocean. After the article discusses the historical context and the circumstances that led to the creation of Silent Spring, its main arguments, the marketing strategies used for its publication, and the international repercussions brought about by the work. Finally, it presents the criticisms directed against her book on pesticides.

Keywords: Rachel Carson; Silent Spring; criticism; contemporary environmentalism; principles of environmental law

Desenvolv. e Meio Ambiente usa uma Licença Creative Commons - Atribuição-NãoComercial-SemDerivações 4.0 Internacional 


\section{Introdução}

Poucos anos atrás, a Câmara Federal aprovou e encaminhou, para apreciação do Senado, o Projeto de Lei n. 6.299/2002 (Brasil, 2002), que propõe modificações no sistema brasileiro de regulação de agrotóxicos, de seus componentes e afins. Apelidado por seus opositores como "Pacote do Veneno", o PL foi apresentado em 2002 pelo então Senador do Mato Grosso e empresário do setor agropecuário, Blairo Maggi. Quando da aprovação do PL pela Câmara Federal, ainda durante a Presidência de Michel Temer, Maggi dirigia o Ministério da Agricultura, Pecuária e Abastecimento - MAPA.

O objetivo central do PL n. 6.299/2002 (Brasil, 2002) seria atualizar a legislação brasileira relativa aos agrotóxicos, inclusive mediante revogação expressa das Leis n. 7.802/1989 e 9.974/2000. Em consequência, flexibilizaria o registro e reduziria os custos dos pesticidas para o setor produtivo, o que indiretamente estimularia o crescimento da produção agrícola. Ocorre que entidades como a Fundação Oswaldo Cruz - Fiocruz (2018) já se manifestaram contrariamente às pretendidas inovações legislativas. Em seu parecer, não estaríamos diante de ações modernizantes ou inovadoras, mas de verdadeiros retrocessos em matéria de saúde pública e de conservação ambiental.

Uma das inovações mais criticadas do PL n. 6.299/2002 (Brasil, 2002) é a mudança da competência administrativa para o registro de pesticidas. Hoje, por força do art. $3^{\circ}$ da Lei Federal n. 7.802/1989, o aludido registro demanda prévia manifestação de "órgãos federais responsáveis pelos setores da saúde, do meio ambiente e da agricultura", in casu, Agência Nacional de Vigilância
Sanitária - ANVISA, Instituto Brasileiro do Meio Ambiente e dos Recursos Naturais Renováveis IBAMA e MAPA, respectivamente. Contudo, com a aprovação do PL n. 6.299/2002, o registro de pesticidas com finalidades agrícolas, nos termos do art. $4^{\circ}$, passaria a competir apenas ao MAPA (Brasil, 2002). Aprovado o PL n. 6.299/2002, ANVISA e IBAMA atuariam no processo como órgãos meramente consultivos. Essa circunstância legal, ponderou a Fiocruz, criaria contexto favorável para o sucesso do lobby dos representantes do agronegócio, ainda que em detrimento da saúde pública e da conservação ambiental, que são interesses coletivos ou difusos (Fundação Oswaldo Cruz, 2018). A celeuma tem atraído a atenção da mídia impressa, televisiva e digital. Além disso, nas mídias sociais, também tem mobilizado grupos e entidades da sociedade civil organizada em prol da agroecologia, da agricultura urbana livre de agrotóxicos e dos assim chamados "alimentos orgânicos".

Como se vê, a "controvérsia dos pesticidas", uma das discussões fundantes do movimento ambientalista contemporâneo, ainda é uma chaga aberta no Brasil. É que a tropicalidade (favorável à difusão e à reprodução de insetos) e a dependência brasileira em relação a um modelo econômico quincentenário, calcado na exportação de commodities agrícolas, colocam os agroquímicos em geral - e os pesticidas, em particular - em uma posição privilegiadíssima na arena política nacional. Há enorme espaço para a relativização da conservação ambiental, da saúde pública, dos direitos dos trabalhadores e dos consumidores ante à permanente necessidade de produzir riquezas, emprego e renda. 
Dada a relevância econômica, política e social da "controvérsia dos pesticidas" em solo brasileiro, surpreende que, em língua portuguesa, haja tão pouca produção literária e científica a respeito da vida, da obra e do legado da estadunidense Rachel Louise Carson. Escritora, bióloga, ícone do movimento ambientalista nos Estados Unidos e no resto do Ocidente, Carson foi uma eficiente divulgadora da matéria, na década de 1960. Silent Spring, o seu multipremiado best seller que trata especificamente dos efeitos indesejados e deletérios dos pesticidas organoclorados, então recém-desenvolvidos, foi traduzido para diversos idiomas - inclusive para o português - e vendeu milhões de cópias em todo o mundo.

O presente artigo visa romper essa intrigante omissão das ciências brasileiras a respeito de Rachel Carson. Síntese de pesquisa bibliográfica e documental a respeito da bióloga e escritora estadunidense, inicialmente, apresenta a sua trajetória pessoal: família, primeiros anos de vida, aspectos de sua formação acadêmica, motivos que a conduziram ao serviço público no US Fish and Wildlife Service e a publicação dos livros a respeito do oceano. Em seguida, apresenta o conteúdo de Silent Spring e o contexto em que foi escrito. Após, elucida as estratégias utilizadas por Carson e por seus apoiadores para transformar Silent Spring em eficiente instrumento de advocacy ambiental. Segue discutindo a mudança da perspectiva da autora a respeito da relação entre seres humanos e natureza, uma metamorfose atravessada por cientistas das mais diversas áreas do saber, dada a - então recente - invenção de armamentos de destruição em massa. Ulteriormente, aborda algumas das críticas que foram dirigidas à Rachel Carson e que ainda hoje povoam a "controvérsia dos pesticidas".
Por derradeiro, avalia os alertas formulados em Silent Spring a partir do conhecimento científico produzido entre 1962 e 2019.

\section{A trajetória pessoal de uma autora consagrada}

Rachel Louise Carson veio ao mundo em uma família presbiteriana de poucas posses. Descendente de escoceses e de irlandeses, Carson nasceu em 27/05/1907, nos arredores de Springdale, Pensilvânia, uma localidade a nordeste de Pittsburg que era pouco mais que uma cidade-dormitório para os trabalhadores da West Penn Power Company (Lear, 1993; Lytle, 2007; Souder, 2012).

Caçula de três filhos, desde criança Carson foi estimulada por sua mãe a observar o mundo natural e a escrever. Publicou em revistas juvenis - em especial, na St. Nicholas Magazine —, chegando a ser premiada por suas composições. "A battle in the clouds", sua primeira história, foi publicada quando a autora tinha pouco mais de 10 anos de idade (Lear, 1993; Lytle, 2007; Meiners et al., 2012; Souder, 2012; Bonzi, 2013; Musil, 2014).

Carson ingressou no Pennsylvania College for Women - PCW em 1929, com a finalidade de aperfeiçoar os seus talentos literários e se tornar uma escritora profissional. Lá, influenciada pela professora Mary Skinker, alterou a sua opção de estudos, de língua inglesa para biologia (Lear, 1993; Quaratiello, 2004; Lytle, 2007; Meiners et al., 2012; Souder, 2012; Bonzi, 2013). Estudou biologia marinha no Woods Hole Marine Biological Laboratory e, em 1932, obteve o grau de mestre em zoologia na Universidade Johns Hopkins. A sua dissertação de mestrado, intitulada "The Development of the 
Pronephros During the Embryonic and Early Larval Life of the Catfish (Inctalurus puncfatus) ${ }^{1}$,", dificilmente revela a sua trajetória profissional ulterior (Beyl, 1992).

Em 1932, logo após obter o título de mestre, os fardos familiares aumentaram bastante. O irmão, Robert, deixou a casa dos pais para morar só. A irmã, Marian, mãe de duas meninas, divorciou-se e ficou inválida, vítima de um quadro agudo de diabetes. Assim, para poder ajudar no custeio das despesas do lar, Rachel Carson teve de abandonar o programa de doutoramento da Universidade Johns Hopkins e dedicar-se integralmente ao emprego de professora (Lear, 1993; Quaratiello, 2004; Lytle, 2007; Souder, 2012).

Em 1935, com o falecimento do seu septuagenário pai, Carson tornou-se a principal provedora da família. Por intervenção da professora e amiga Mary Skinker, passou a trabalhar em tempo parcial no US Bureau of Fisheries, onde redigia roteiros de programas de rádio acerca da vida marinha. Carson completava seus rendimentos elaborando artigos sobre a história natural da Baía de Chesapeake para o jornal Baltimore Sun: nessa época, cada artigo publicado the rendia US\$ 20 (Quaratiello, 2004; Lytle, 2007; Meiners et al., 2012; Souder, 2012).

Em 1936, Rachel Carson iniciou uma carreira de 15 anos como cientista e editora na agência ambiental estadunidense, o US Fish and Wildlife Service. Em 1937, a partir dos dados e pesquisas aos quais tinha acesso como servidora federal, publicou um artigo no The Atlantic Montlhy, intitulado "Undersea". Por sugestão de editores e colegas, Carson revisou e ampliou o artigo para transformá-lo em livro. No ano de 1941, publicou Under the
Sea-wind, traduzido para a língua portuguesa sob o título: "Sob o mar-vento" (Carson, 2011), produto final desse trabalho (Lear, 1993; Lytle, 2007; Meiners et al., 2012).

A obra recebeu críticas favoráveis que não se converteram em boas vendas, quiçá pelo fato de o público estar mais preocupado com as consequências imediatas do ataque japonês à base militar estadunidense de Pearl Harbor/Havaí. O evento ocorreu menos de dois meses depois do lançamento do livro de Carson e motivou os EUA a ingressarem na Segunda Guerra Mundial (Beyl, 1992; Lytle, 2007; Meiners et al., 2012).

Carson teve mais sorte com a publicação, em 1951, do segundo livro que redigiu ao longo de madrugadas insones, The Sea Around Us, editado pela Oxford University Press e traduzido para a língua portuguesa sob o título: "O mar que nos cerca” (Carson, 1956). Com ele, Carson e seus editores inauguraram a estratégia de publicar excertos selecionados em revistas de grande circulação antes da publicação do livro propriamente dito. Quer pela estratégia de marketing, quer pelo conteúdo do trabalho, The Sea Around Us (Carson, 1956) tornou-se um best seller: em dezembro de 1951, vendia mais de 4 mil cópias por dia. Em 1952, o livro recebeu o National Book Award (Beyl, 1992).

The Sea Around Us, trouxe a Rachel Carson notoriedade e independência financeira. O dinheiro auferido com a venda dos seus exemplares permitiu que a autora adquirisse uma propriedade na costa do Maine e que se desligasse do US Fish and Wildlife Service, em 1952. Ademais, a partir de então, Carson pode se dedicar exclusivamente à carreira de escritora (Lytle, 2007).

\footnotetext{
${ }^{1}$ Em tradução livre: "O desenvolvimento do proto-rim durante a vida embrionária e o estágio larval do Peixe-gato (Inctalurus puncfatus)".
} 
Em 1955, publicou, pela editora Houghton Mifflin Co, mais um estudo sobre o oceano, o livro The Edge of the Sea, traduzido para o português sob o título "Beira-mar" (Carson, 1955; 2010a). A obra consagrou Rachel Carson como escritora científica nos EUA (Bonzi, 2013), embora jamais tenha alcançado o mesmo sucesso de vendas ou de críticas do aclamado The Sea Around Us (Lytle, 2007).

Desse modo, em setembro de 1962, quando publicou Silent Spring (Carson, 1962; 2010b), também pela editora Houghton Mifflin Co, Carson já era conhecida como renomada cientista e competente escritora. Ela era capaz de comunicar, ao público em geral, com seriedade, independência acadêmica, financeira e por meio de linguagem acessível, o resultado de achados científicos (Beyl, 1992; Meiners et al., 2012).

A publicação de Silent Spring, o "poison book" - tal como o apelidara uma amiga próxima da autora - rendeu fama, prêmios, reconhecimento e muitos inimigos a Rachel Carson. Por um lado, a autora foi convocada a testemunhar, no Parlamento estadunidense, acerca dos riscos inerentes aos pesticidas, uma demonstração pública e inquestionável de reconhecimento. Carson também foi empossada como membro da Academia Americana de Artes e Letras e agraciada, entre diversos outros prêmios, com a Medalha da National Adubon Society, a Sociedade Adubon ${ }^{2}$. Por outro lado, Rachel Carson foi duramente atacada pela indústria química e por cientistas defensores do uso de pesticidas, tais como o diclorodifeniltricloroetano - DDT (Lytle, 2007; Meiners et al., 2012; Souder, 2012).

\section{Rachel Carson e os pesticidas}

No início do período que Hobsbawm (1995) denominou "Era de Ouro do Capitalismo", isto é, dos 25 anos que sucederam a Segunda Guerra, o pleno emprego e a pesquisa técnico-científica alteraram o padrão de vida das famílias. A maior disponibilidade de renda estimulou o consumo (e a oferta) em massa. Os transistores permitiriam a redução abrupta do custo de fabricação do rádio e da televisão contribuindo para a sua popularização (Prost \& Vicent, 1992) e para a criação de uma mídia voltada para as massas. Discos de vinil induziram a criação de uma indústria cultural. Nessa época, "a revolução tecnológica entrou na consciência do consumidor em tal medida que a novidade se tornou o principal recurso de venda para tudo" (Hobsbawm, 1995, p. 261). O lema: "Better things for better living... Through chemistry", da gigante Du Pont (empresa americana que constitui, até os dias atuais, uma das maiores indústrias químicas do mundo) transmite com razoável precisão o espírito da época (Lytle, 2007; Meiners et al., 2012).

Esse é o momento histórico da invenção e da difusão dos pesticidas orgânicos, em especial o DDT, que foi o primeiro deles. As propriedades inseticidas do DDT eram conhecidas pelo menos desde 1939. Não obstante, o produto, sintetizado por Zeidler em 1874 (Flores et al., 2004) difundiu-se no mercado norte-americano e europeu somente depois de 1944 (Gunter \& Harris, 1998), como adaptação, para a agricultura, de uma tecnologia sanitária utilizada durante a Segunda Guerra. Durante os anos

\footnotetext{
${ }^{2}$ Trata-se de uma associação civil sem fins lucrativos, com propósitos conservacionistas e sediada em Nova Iorque. Uma das mais antigas e respeitadas ONG ambientalistas dos EUA, a Sociedade Adubon foi fundada em 1905 e o seu nome homenageia o ornitólogo e naturalista, John J. Audubon, autor do clássico "The birds of America".
} 
bélicos, o DDT foi utilizado como inseticida contra vetores de doenças letais como o tifo e a malária, às quais os soldados e a população civil estavam cotidianamente expostos (Gunter \& Harris, 1998; Souder, 2012).

Adicionalmente, havia cumplicidade entre os altos escalões do Departamento de Agricultura dos EUA - USDA e a indústria química, muito valorizada por conta das tecnologias desenvolvidas ao longo da Guerra (Lytle, 2007). Milhares de vidas humanas, civis e militares, foram poupadas durante os conflitos mundiais dadas as pulverizações em massa que visavam à erradicação dos vetores de doenças (Meiners et al., 2012; Souder, 2012). Na propaganda da época, a bomba atômica e a bomba inseticida haviam lutado e ganhado a guerra em favor dos Aliados.

No clima da Guerra Fria, acreditava-se que armamentos químicos seriam indispensáveis na guerra contra o comunismo, tanto quanto na guerra contra as pragas agrícolas que, supostamente, ameaçavam a segurança alimentar dos EUA. Conforme texto de Lytle, em tradução livre:

[...]. As indústrias químicas e farmacêuticas haviam adquirido grande prestígio pelo papel vital desempenhado durante a Segunda Guerra. Os médicos das forças armadas utilizaram a penicilina, recém-descoberta, para tratar soldados portadores de DST ou feridas infeccionadas. Aviões bombardeavam toneladas de "napalm", uma gasolina altamente inflamável em formato gelatinoso, para forçar as tropas inimigas a deixarem suas posições fortificadas. O DDT se mostrou importantíssimo no controle de doenças transmitidas por insetos tais como mosquitos e piolhos, que sempre, e em todo o mundo, foram flagelos para os exércitos. A maioria dos cientistas estava convencida de que esses pesticidas não representavam perigo significativo aos humanos, aos animais domésticos e à fauna selvagem. Carson testemunhou [...] que nos $\operatorname{anos} 50$ a Guerra Fria ofereceu novos incentivos para a expansão do arsenal químico do país, quer em forma de armas de guerra, quer em forma de produtos destinados à proteção da agricultura dos EUA. Os militares testaram um amplo espectro de armas químicas que, ao contrário da bomba atômica, poderiam neutralizar um inimigo sem o problema da destruição física generalizada. Cientistas desenvolveram novas classes de inseticidas, herbicidas e fungicidas potentes, para eliminar as pragas. Os entomologistas do governo e da indústria química empregavam livremente metáforas que comparavam insetos a comunistas (Lytle, 2007, p. 135-137).

Desse modo, não se estranha a ampla propaganda em favor dos novos pesticidas orgânicos, ao longo das décadas de 1940 e 1950. Na TV, no rádio e na mídia impressa, divulgava-se que esses produtos não representavam qualquer ameaça aos humanos, aos animais domésticos ou à segurança dos alimentos, sendo danosos apenas aos insetos e às demais pragas.

E a propaganda era agressiva. O filme " $D D T$ versus Malária”, gravado em 1946 por ocasião de uma campanha contra a malária no distrito de Kisumu, a nordeste do Quênia, por exemplo, mostra a incrível (e, hoje, inconcebível) cena de um suposto médico sanitarista, comendo uma colherada de DDT, a fim de convencer a tribo dos Kipsigis de que a substância era mesmo segura ${ }^{3}$ (Garnham, 1946). A publicidade impressa não ficava para trás. Imagens domésticas eram corriqueiramente utilizadas para vender pesticidas: crianças, cães e donas

\footnotetext{
${ }^{3}$ Das informações disponíveis a respeito do filme, consta a de que fora inicialmente gravado como um documentário. Mais tarde, contudo, chegou-se à conclusão de que poderia ser utilizado como propaganda em favor do DDT.
} 
de casa eram as grandes estrelas desses anúncios. $\mathrm{O}$ anúncio do DDT da Pennsalt Chemicals, divulgado na Time Magazine, contém a ilustração de animais domésticos, de vegetais e de uma dona de casa cantando, como que em coro, o refrão: " $D D T$ is good for me-e-e!". O texto do anúncio retrata o DDT como uma verdadeira panaceia contemporânea, que aumenta a produtividade das lavouras e dos rebanhos, bem como a segurança dos lares.

As campanhas publicitárias foram bem-sucedidas, até porque, além de eficientes na eliminação de pragas, os novos pesticidas eram relativamente baratos (Souder, 2012). Desse modo, a década de 1950 testemunhou diversas iniciativas, públicas e privadas, de pulverização de herbicidas e pesticidas artificiais orgânicos em lavouras, jardins, pastos e mesmo em pessoas.

Ocorre que, rapidamente, os efeitos indesejados das pulverizações começaram a ser percebidos e estudados. Aqui e acolá, vozes minoritárias - embora persistentes - se levantavam na grande mídia impressa denunciando o uso abusivo de pesticidas (Souder, 2012). Entre os inconformados, além de associações conservacionistas, havia servidores do próprio USDA e das suas respectivas entidades subsidiárias.

Analisando edições do New York Times entre 1944 e 1961, ou seja, anteriores à publicação de Silent Spring (Carson, 1962; 2010b), Gunter \& Harris (1998) descobriram cerca de 230 matérias que versavam sobre pesticidas. Pelo menos metade dessas matérias faz referências positivas aos novos pesticidas artificiais orgânicos. Entre as matérias com referências negativas, cerca de $1 / 3$ partiu de representantes e pesquisadores do USDA ou de suas entidades subsidiárias.
Noutros termos, para Gunter \& Harris (1998), ironicamente, o USDA suscitou na grande mídia, por longo período, as mesmas questões pelas quais, anos depois, seria atacado. É que o USDA assumiu, política e economicamente, a despeito do entendimento dos seus técnicos e das suas entidades subsidiárias, a dianteira das campanhas de pulverização aérea de pesticidas para a erradicação de insetos tais como o besouro japonês, a formiga lava-pés e a mariposa cigana. Essas campanhas foram duramente criticadas em Silent Spring (Carson, 2010b).

Carson publicou Silent Spring na segunda onda de críticas contra as pulverizações aéreas de pesticidas, depois do redundante fracasso dos programas federais de erradicação da mariposa-cigana e da formiga-lava-pés. Antes de batizar aquele que se tornaria o seu grande best seller como "Silent Spring", a autora considerou pelo menos outros três títulos: "The war against nature", "At war with nature" e "Man against the Earth", que deixam bem claro qual é a tônica da obra (Lytle, 2007).

Nessa época, além da constatação empírica dos perigos representados pelos pesticidas, os estadunidenses estavam alarmados com duas outras crises sanitárias veiculadas na grande mídia. E tal como a controvérsia dos pesticidas, essas crises sanitárias - as ameaças nucleares e a descoberta dos efeitos adversos da talidomida - também abalaram a confiança da população no Poder Público (Lytle, 2007; Souder, 2012; Davis, 2013).

A talidomida foi desenvolvida na Alemanha Ocidental a partir de 1954. Produzida inicialmente como sedativo, a droga passou a ser considerada verdadeira panaceia medicamentosa. Além de sedação, a talidomida foi utilizada em hipnoses, no combate a inflamações, no controle de gripes e de enjoos gestacionais. Autorizada pelos órgãos 
de fiscalização europeus e considerada inofensiva, descobriu-se, em pesquisa publicada em 1961, que estava diretamente relacionada à má-formação fetal. O uso irrestrito da talidomida é responsável pela vitimização de mais de 10.000 pessoas em 46 países (Brasil incluído), pessoas que ficaram conhecidas como "bebês da talidomida". Atualmente, pesquisas têm apontado a talidomida como poderoso imunossupressor e como promessa no combate a doenças como hanseníase, Aids, neoplasias, artrite reumatoide, tuberculose crônica, doença de Behçet e doença de Crohn (Saldanha, 1994; Borges \& Fröehlich, 2003; Lytle, 2007).

Também os testes nucleares colocaram em xeque a confiança dos estadunidenses nos seus governantes. Entre 1945 e 1962 ocorreram 423 detonações nucleares promovidas pelos EUA, URSS, Grã-Bretanha e França. Essas detonações tiveram duros custos ambientais, dentre os quais: a) chuva de granizo radioativa na Austrália, em 1952; b) chuva radioativa no Estado de Nova Iorque/EUA, em 1953; c) cinzas radioativas sobre as Ilhas Marshall, provocando a contaminação de $18 \mathrm{mil} \mathrm{km}{ }^{2}$ de oceano, a contaminação dos peixes e dos pescadores japoneses que estavam embarcados no Lucky Dragon n. 05 (McCormick, 1992; Souder, 2012).

Desconfiança em relação à capacidade do Estado em garantir a integridade sanitária dos cidadãos, emergência de problemas ambientais globais, riscos de destruição ou de contaminação em grandes proporções. Tal é o contexto da publicação de Silent Spring (Carson, 1962; 2010b), da subsequente popularização da "controvérsia dos pesticidas" testemunhada ao longo da década de 1960 e do próprio nascimento do ambientalismo contemporâneo.

\section{Breve síntese de Primavera Silenciosa}

O trecho mais conhecido de Silent Spring é o primeiro capítulo, intitulado "Uma fábula para o amanhã". Com esse texto, Carson atraiu a atenção do grande público para o problema dos pesticidas. Por outro lado, esse mesmo texto contribuiu para que lhe fossem dirigidas acusações de se valer de estratégias "alarmistas", "sensacionalistas" e de uma visão "mística" acerca da existência de um suposto equilíbrio natural pré-existente, recém-destruído pela química.

Sem dúvida, trata-se de uma passagem eloquente. Todavia, embora dê o tom do conteúdo de Silent Spring, "Uma fábula para o amanhã " está longe de constituir a fina flor dos argumentos sustentados pela autora em favor da restrição do uso de pesticidas. Trata-se, antes, de uma "isca" para despertar a curiosidade do leitor para os próximos capítulos. A trama é construída a partir da ciência e da imaginação, retórica típica de um gênero literário que fazia - e ainda faz - muito sucesso entre o público em geral: a ficção científica.

Carson escreveu Silent Spring como pesada crítica aos vários programas de dedetização, levados a efeito em fazendas, cidades, Estados e macrorregiões dos EUA, ao longo da década de 1950, sob orientação e fomento do USDA. Narra a autora que, em geral, esses programas - denominados "programas de erradicação" ou de "controle de pragas", eram executados por meio de pulverização aérea indiscriminada de pesticidas tais como a aldrina, a dieldrina, o heptacloro, o DDT, o paratião e a endrina. Seja pela avidez por lucro fácil, seja pela ignorância dos usuários, era comum que tais produtos fossem lançados no meio ambiente em quantidades 
muitas vezes superiores àquelas recomendadas pelo USDA ou mesmo pelos próprios fabricantes.

No livro, a autora pretendeu estabelecer (ou, ao menos, sugerir) a existência de nexo causal entre a pulverização de aldrina, dieldrina, heptacloro, DDT, paratião e endrina e os eventos negativos inesperados testemunhados por criadores de gado leiteiro, apicultores, criadores de cavalos, horticultores, pescadores, criadores de animais domésticos, ornitólogos, entomologistas, todos atuantes nas regiões pulverizadas.

Para tanto, Carson utilizou ampla diversidade de fontes. Foram consultados estudos e recomendações do USDA, do Departamento Florestal, do US Fish and Wildlife Service, relatórios produzidos pelo Parlamento dos EUA, estudos de órgãos ambientais estaduais e relatórios de entidades civis de proteção à vida selvagem. Carson também trouxe ao seu livro resultados obtidos nas pesquisas em medicina (inclusive em oncologia, saúde ocupacional e endocrinologia), em medicina veterinária, em farmacologia, em agronomia, em entomologia, em genética e em zoologia. Por derradeiro, a autora também contatou diretamente pesquisadores e cidadãos preocupados com a relação desvantajosa entre os custos e os benefícios do uso abusivo de pesticidas (Carson, 1962; 2010b).

Silent Spring (Carson, 1962; 2010b) é saturado com a exposição de casos de comprovada, evidente ou de muito provável contaminação de animais selvagens, domésticos e mesmo de seres humanos por pesticidas. A autora traz relatos exaustivos de contaminação em diversas localidades dos EUA, Canadá, Reino Unido, além de alguns poucos registros na África e na Ásia. Carson mostra como esses episódios teriam levado à indesejada mortandade de mamíferos, aves, peixes, crustáceos e de insetos benéficos à agricultura, bem assim de espécimes vegetais apreciados por humanos. Tudo em decorrência da aplicação indiscriminada e descuidada de substâncias amplamente utilizadas para proteger a produção agrícola contra a ação de parasitas.

Em Silent Spring, Rachel Carson (1962; 2010b) afirmou que os agroquímicos utilizados nos programas federais de erradicação de pragas agrícolas não estavam suficientemente testados. Argumentou que tais programas, patrocinados pelo USDA e custeados pelos contribuintes estadunidenses, sequer consideraram os dados e estudos científicos já disponíveis. Denunciou, desse modo, que o Poder Público, por meio do USDA, estaria privilegiando o lucro dos fabricantes de agroquímicos em detrimento da saúde e da propriedade privada dos cidadãos estadunidenses, em detrimento do Erário e das diversas atividades econômicas incompatíveis com as pulverizações de pesticidas.

Apelidando o seu tempo como a "Era dos Venenos" (Carson, 2010, p. 152), a autora problematizou a banalização, a naturalização do uso cotidiano de pesticidas. Alertou para o fato de que tais produtos, alguns dos quais centenas de vezes mais perigosos do que medicamentos controlados, são vendidos sem nenhum tipo de restrição em supermercados, casas de ferragens, armazéns e lojas especializadas em artigos de jardinagem: "bem em frente aos picles e às azeitonas [...] e ao lado dos sabonetes e dos sabões para lavar a roupa" (Carson, 2010, p. 152-153). Não fosse suficiente, tanto a composição dos agroquímicos quanto os seus riscos normalmente seriam estampados em letras miúdas, sendo raramente levados em consideração pelos consumidores. Por fim, as peças publicitárias dos agroquímicos asseguravam-se em transmitir uma falsa sensação de segurança aos usuários. 
Carson também observou que, como resultado direto da tolerância do Poder Público para com a pulverização dos compostos organoclorados sobre as lavouras, a dieta do norte-americano médio seria rica em ingestão de pesticidas (Carson, 1962; 2010b). É que, como os referidos agroquímicos não seriam elimináveis pela lavagem ou pelo cozimento, poderiam ser cotidianamente encontrados em frutas, verduras, legumes, carnes, leite e derivados, largamente consumidos pelas famílias. Ademais, como são armazenados em gordura, traços de pesticida seriam encontrados até mesmo no leite materno, representando inaceitável risco sanitário a bebês humanos.

A autora também argumentou que os "níveis de tolerância" a agroquímicos estabelecidos pelo Poder Público, representado pela Administração de Alimentos e Medicamentos - FDA, não forneciam garantias suficientes de segurança aos consumidores. Inicialmente, porque até mesmo a indústria química reconhecia que os fazendeiros tinham o péssimo hábito de misturar agroquímicos ou de utilizar concentrações muito maiores do que as recomendadas (Carson, 1962; 2010b). O Estado, por sua vez, não dispunha de fiscais em número suficiente para inspecionar amostras representativas da produção agrícola em todo o território nacional.

Ademais, para Carson seriam falaciosos os próprios pressupostos utilizados pela FDA para fixar os tais "níveis de tolerância". Isso porque, diversamente do que ocorre com cobaias de laboratório, seres humanos estão expostos diariamente a um sem-número de pesticidas. Noutros termos, os "níveis de tolerância" estatuídos pela FDA desconsiderariam quer os montantes acumulados, quer as interações entre os agroquímicos consumidos por uma mesma pessoa ao longo da sua existência (Carson, 1962; 2010b).

\section{A publicação de Silent Spring e o advocay ambiental}

Rachel Carson, seus parceiros e editores estavam conscientes de que, uma vez publicado, Silent Spring receberia severas críticas de representantes e de aliados da indústria química, o que realmente ocorreu (Lytle, 2007; Souder, 2012; Musil, 2014). Por isso, para preservar a credibilidade da mensagem que pretendiam transmitir, buscaram desassociar o livro de toda e qualquer manifestação verde considerada, à época, excessiva ou radical (vegetarianos, veganos, produtores de orgânicos, defensores dos direitos dos animais), mesmo que, pessoalmente, Carson simpatizasse com algumas delas.

Pelo mesmo motivo, Carson e apoiadores valeram-se de conexões no mundo acadêmico para fortalecer Silent Spring com dados empíricos. Para conferir legitimidade à publicação, buscaram o apoio da mídia, o apoio de associações civis e a simpatia de pesquisadores de eminentes universidades americanas, tais como Edward Wilson, em Harvard; George Wallace, na Michigan State University e Joseph Hickey, na Universidade de Wisconsin.

Ademais, uma vez que Silent Spring foi concluído, em cuidadoso trabalho de marketing, os parceiros de Carson distribuíram exemplares inéditos a personalidades políticas estratégicas, tais como o Secretário do Trabalho de John Kennedy, Frances Perkins; a Senadora Maurine Neuberger; a Congressista Leonor Sullivan e William O. Douglas, membro da Suprema Corte dos EUA (Lytle, 
2007; Musil, 2014). Líderes de associações civis norte-americanas historicamente engajadas na luta por direitos coletivos e difusos também receberam exemplares de Silent Spring antes da sua disponibilização nas livrarias para o grande público.

Seguindo a fórmula de sucesso inaugurada com The Sea around Us (Carson, 1956), excertos de Silent Spring foram inicialmente publicados na revista New Yorker nos dias 16, 23 e 30/06/1962, no formato de um artigo dividido em seções. A repercussão foi enorme: só na New Yorker, a discussão acerca do tema rendeu mais de 50 editoriais e publicações em 20 colunas (Beyl, 1992; Souder, 2012).

O grande público estadunidense estava particularmente sensível a informações concernentes aos riscos sanitários de inovações científico-tecnológicas. À época, um conflito nuclear mundial parecia iminente e inevitável (recorde-se, a esse respeito, a "Crise dos Mísseis" de Cuba, de outubro de 1962, contemporânea à publicação de Silent Spring). Por sua vez, a má-formação de um sem-número de bebês em decorrência do uso de talidomida por suas mães era a prova viva da ineficiência da fiscalização sanitária levada a efeito pelo Poder Público (Lytle, 2007; Souder, 2012; Davis, 2013).

Como consequência do impacto que Silent Spring provocou no grande público, Carson foi convidada a apresentar as suas ideias em congressos, seminários, grupos de estudo e mesmo para o Parlamento estadunidense. Depois disso, a rede de contatos em prol da erradicação do DDT foi progressivamente ampliada, envolvendo o Secretário do Interior de John Kennedy, Stewart Udall, o diretor do Sierra Club, David Brower, e Howard Zahniser, da Wilderness Society (Lytle, 2007; Musil, 2014).
Além dessa repercussão imediata, ponderações de Rachel Carson em Silent Spring também laboraram em favor da regulamentação ambiental internacional. Como já discutido, Carson (1962; 2010b) criticou duramente a imprudência na utilização de agroquímicos pouco testados e cujos impactos ambientais ainda eram desconhecidos. Chamou atenção para o fato de que os possíveis efeitos deletérios dos pesticidas eram desconhecidos da população direta e indiretamente afetada por eles. Irresignada, alertou para o fato de que os prejuízos advindos do uso irresponsável dos pesticidas vinham sendo distribuídos entre todos os cidadãos quando, na verdade, deveriam ser suportados exclusivamente por aqueles que os provocaram.

As reivindicações de Carson transformaram-se em bandeiras do movimento ambientalista (Quaratiello, 2004; Meiners et al., 2012), reverberaram nos tratados e convenções internacionais e consagraram-se como princípios gerais de direito ambiental, especialmente quando da Conferência das Nações Unidas sobre o Meio Ambiente e o Desenvolvimento -ECO/92. Fala-se, aqui, dos princípios da prevenção, da precaução, da informação, da participação e do poluidor-pagador.

Os Princípios 15 e 17 da Declaração do Rio sobre o Meio Ambiente e Desenvolvimento contemplam a precaução e a prevenção como pressupostos do desenvolvimento sustentável. Considerando que, consumando o dano, a recuperação ambiental é incerta e custosa, ambos princípios demandam que o administrador realize um juízo de futuro. Em outros termos, ao invés de atuar reagindo e corrigindo, esses princípios sugerem que o administrador atue planejando, prevendo e prevenindo (Machado, 1993; Meiners et al., 2012). 
Nessa linha, o princípio da prevenção impõe a realização de estudos prévios como obrigação dos empreendedores, obrigação essa que deverá ser exigida pelos Estados signatários da Declaração do Rio. O propósito de tais estudos é antever os prováveis impactos ambientais dos empreendimentos, medida que permite evitar ou, ao menos, mitigar esses impactos.

A precaução, o mais polêmico dentre os princípios de direito ambiental, vai mais além. Esse mandamento inverte a lógica liberal por meio da qual a proibição de determinada mercadoria ou empreendimento deva estar fundada em provas científicas da sua periculosidade. Adotando-se a precaução, é o empreendedor quem passa a ter o ônus de provar que o seu negócio ou a sua mercadoria são inofensivos à coletividade. Em outros termos, na existência de controvérsia científica a respeito do potencial poluidor de determinado produto ou atividade privada, o Estado terá o múnus de evitá-los ou restringi-los ao máximo. Desse modo, a proibição de determinado produto ou atividade deixa de exigir certeza para exigir tão somente a probabilidade de dano. Daí a polêmica. Os críticos do princípio da precaução argumentam que, em se adotando esse tipo de mandamento, a humanidade estará condenada a jamais progredir, dado que o processo de inovar implica a aceitação de riscos desconhecidos (Giddens, 2009; Meiners et al., 2012).

Os Princípios 10, 18 e 19 da Declaração do Rio contemplam a participação e a informação como pressupostos indissociáveis do desenvolvimento sustentável. Estabelecem, inicialmente, um dever de agir com transparência. Torna-se obrigação dos signatários manter a sua própria população e outros Estados nacionais informados a respeito de impactos ambientais locais, regionais, nacionais ou transfronteiriços. O objetivo é que todos os sujeitos potencialmente afetados por empreendimentos poluidores possam opinar, decidir e acompanhar a fiscalização estatal (Machado, 1993).

O Princípio 16 da Declaração do Rio, conhecido como "Princípio do Poluidor-Pagador", estabelece que, ab initio, compete ao empreendedor arcar com os custos da poluição provocada pelo seu empreendimento. $\mathrm{O}$ mandamento seria uma forma de internalizar, nas mercadorias, os seus custos ambientais. O seu objetivo é evitar a socialização dos prejuízos e, consequentemente, a ocorrência da "Tragédia dos Comuns", isto é, a sobre-exploração e a degradação dos bens comunais (Hardin, 1968; Machado, 1993).

Observe-se que os referidos princípios de direito ambiental também foram contemplados na legislação brasileira. Citam-se, especialmente, o Artigo 225 da Constituição Federal de 1988 (Brasil, 1988), a Lei da Política Nacional do Meio Ambiente - Lei no 6.938/1981(Brasil, 1981) e a Lei do Sistema Nacional de Unidades de Conservação da Natureza - SNUC, Lei nº 9.985/2000 (Brasil, 2000).

\section{Rachel Carson, do oceano aos pesticidas}

A prestigiada trilogia a respeito dos oceanos (Under the Sea-wind, The Sea around Us e The Edge of the Sea) e o "poison book", Silent Spring, foram escritos e publicados pela mesma pessoa. Apesar disso, a produção de Carson deixa claro que, ao longo das duas décadas que separam o primeiro e o último livro, a sua compreensão a respeito do que seria a natureza e do que fazer com a natureza passou por grandes mudanças. 
Em Under the Sea-wind, ainda no início de sua carreira como escritora, Carson (2011) não descrevia os seres humanos como um problema para a vida marinha. Ela retratou o pescador, por exemplo, como mais um entre muitos agentes de transformação e de perpetuação do equilíbrio dinâmico do oceano: aqui o homem é retratado como parte da teia de vida dos mares. Leia-se:

Os pescadores trabalham depressa para retirar as tainhas da rede e lança-las nos barcos ali perto. Com hábil sacudida na rede, eles jogam sobre a praia os pequenos peixes que ficaram presos pelas guelras na malha de cordas. São jovens trutas-marinhas, pampos, tainhas da desova do último ano, cavalas, sargos-de-dente e garoupas. [...]. Em breve, os corpos desses jovens peixes - pequenos demais para venda ou consumo - se transformarão em resíduos na região acima da linha da água; a vida se esvairá deles por falta de meios para atravessar uns poucos metros de areia seca e retornar ao oceano. Alguns desses pequenos corpos serão levados mais tarde pelo mar; outros permanecerão além do alcance das marés, em meio ao refugo formado por pedaços de algas, aveias-do-mar e conchas. Assim, infalivelmente, o mar provê material para os caçadores dos limites da maré. [...]. Então, as gaivotas chegaram [...] e elas banquetearam-se com os peixes. Enquanto as gaivotas disputavam o alimento, duas aves menores [...] caminhavam cautelosamente entre elas, arrastando peixes para mais longe do mar, a fim de devorá-los mais tarde. [...]. Depois do crepúsculo, os caranguejos-fantasmas viriam em legiões, saindo de seus abrigos em buracos na areia para enxamear sobre o lixo, removendo os últimos vestígios de peixe. Novamente, as pulgas-da-areia se juntariam a eles e tratariam de transferir para seus corpos o material dos cadáveres dos peixes. De fato, no mar nada é perdido. A morte de uma criatura permite que outra viva, e os preciosos elementos da vida vão sendo transferidos vez após outra, numa cadeia infinita. (Carson, 2011, p. 78 e 79).

Todavia, essa abordagem do ser humano como mais um agente do equilíbrio ecológico foi abandonada em Silent Spring, talvez pela maior visibilidade dos impactos ambientais das atividades antrópicas no pós-guerra. De fato, o potencial destrutivo das intervenções humanas tornou-se muito mais evidente na década de 1960, quando da publicação de Silent Spring, do que o era na década de 1940, quando da publicação de Under the Sea-wind.

Ou seja, no início de sua carreira como escritora, Carson - como ocorria com os demais biólogos e naturalistas - estava convencida de que a natureza era uma totalidade em equilíbrio e sobre a qual os homens tinham pouca ou nenhuma influência. Por bons motivos, contudo, essa convicção não perdurou nos seus últimos anos de vida. Carson passou pelas duas Guerras Mundiais. Ela testemunhou o advento da Era Atômica, o lançamento das bombas nucleares em Hiroshima e em Nagasaki, os testes atmosféricos com a bomba de hidrogênio, a Revolução Verde, o Dust Bowl ${ }^{4}$, a proliferação de agroquímicos, o surgimento de novos medicamentos, cada vez mais potentes, a letalidade das emissões de gases poluentes na atmosfera ${ }^{5}$.

\footnotetext{
${ }^{4}$ Série de mais de 200 tempestades de poeira que atingiram as Grandes Planícies dos EUA, entre 1934 e 1937 . Fenômeno provocado pela agricultura predatória.

${ }^{5}$ Nos EUA, caso emblemático de poluição do ar é aquele ocorrido em Donora, Pennsylvania, em 1948. Donora era uma cidade com cerca de 13 mil habitantes, situada a $30 \mathrm{~km}$ de Pittsburgh. Gases venenosos eram emitidos pela U.S. Steel's Donora Zinc Works e acabaram inalados pela população local em decorrência de inversão térmica e do consequente efeito estufa. Em apenas cinco dias, mortes e doenças respiratórias — inicialmente atribuídas à asma — abateram quase metade dos habitantes da cidade. O incidente abriu caminho para a edição, em 1955, do Clean Air Act (Musil, 2014; Davidson, 1979; McCormick, 1992).
} 
Como bióloga ciente do longo processo evolutivo atravessado pelas diferentes formas de vida, Carson sabia que o tempo dos humanos não era mais do que um piscar de olhos na história do planeta Terra, história essa medida em bilhões de anos. Mas Carson também sabia que, mesmo nesse estreitíssimo tempo, o Homo sapiens já havia promovido mudanças radicais: extinguiu espécies, criou híbridos, transformou paisagens e ecossistemas. Em outros termos, tais como os oceanos, as marés, o movimento das placas tectônicas e o processo de rotação do globo, os seres humanos haviam se tornado agentes determinantes do curso do processo evolutivo (McCormick, 1992).

Por isso, de confiante nos seres humanos como agentes de equilíbrio ecológico, tornou-se alguém que passou a vê-los como potenciais adversários da grande teia da vida. Em consequência, de bióloga inicialmente dedicada à contemplação e à descrição do mundo natural, uma literatura típica do século XIX, Rachel Carson foi instigada a se dedicar à crítica e à militância ambiental (Meiners et al., 2012). Da episteme, Carson migrou para a prudentia. E essa transição por que passou a autora não foi um fenômeno isolado. Antes, afetou o campo científico como um todo.

O desenvolvimento das armas atômicas e a percepção da ameaça que elas representavam (e ainda representam) forçaram os cientistas a compreenderem que o seu trabalho não estava confinado aos laboratórios. Noutros termos, os armamentos de destruição em massa desnudaram ciência e a técnica de sua suposta neutralidade política. Desse modo, questões éticas tais como "qual deve ser o limite da ciência?" passaram a ser suscitadas por atores vinculados às mais diversas áreas do saber.
Um conhecido exemplo desse rompimento de fronteiras entre a ciência e a ética é a célebre crise de consciência sofrida por Julius R. Oppenheimer, físico responsável pelo "Projeto Manhattan", após a detonação das Bombas de Hiroshima e Nagazaki (Emico, 2015). Outro exemplo bastante eloquente é a publicação do Manifesto Russell-Einstein, em 1955. O texto, subscrito por notórios cientistas da época (Max Born, Percy W. Bridgman, Albert Einstein, Leopold Infeld, Frederic Joliot-Curie, Herman J. Muller, Linus Pauling, Cecil F. Powell, Joseph Rotblat, Bertrand Russell e Hideki Yukawa), é um chamado dos humanos à razão: a escalada atômica e o desenvolvimento da bomba de hidrogênio alcançara níveis inaceitáveis, de modo que uma guerra poderia facilmente dizimar toda a espécie humana (Barros, 2005).

\section{57 anos de críticas a Rachel Carson e a Primavera Silenciosa}

Em Silent Spring, Rachel Carson chamou a atenção para o fato de que o uso abusivo de pesticidas implicava riscos elevados e incertezas, quer para o meio ambiente, quer para a saúde pública. Os argumentos esposados no "poison book" colocaram em xeque premissas confortáveis, quais sejam: 1. A existência de regulação seria condição suficiente para assegurar a saúde pública; 2 . Técnicos e cientistas conseguem dimensionar todas as implicações de seus inventos; 3 . O avanço técnico sempre traz mais benefícios que ameaças; 4 . Os humanos são largamente imunes às alterações ambientais (Lytle, 2007; Hecht, 2012).

Silent Spring provocou grande repercussão, quer no campo científico, quer no campo da ética 
e da política (Bourdieu, 1983). Essas repercussões são ora atribuídas às credenciais cientificas e literárias de Rachel Carson; ora à estratégia de marketing utilizada para a publicação do livro; ora aos temores insuflados na população estadunidense pela corrida nuclear; ora ao escândalo acerca dos efeitos teratogênicos da talidomida que, tal como os pesticidas, era um produto da indústria química pouco testado e de efeitos colaterais nefastos; ora ao fato de Silent Spring ter angariado apoio de associações civis, políticos e cientistas (Lear, 1993; Lytle, 2007; Meiners et al., 2012; Souder, 2012; Bonzi, 2013; Davis, 2013; Musil, 2014).

No campo científico, os atores dividiram-se em apoiadores e críticos de Rachel Carson. Alguns dos que admiravam o trabalho da autora deram prosseguimento à sua abordagem de pesquisa, isto é, à análise dos impactos das novas tecnologias na natureza e na saúde humana. Outros, dentre os que lhe eram contrários, aderiram a certa retórica anti-Carson, povoada por discriminação de gênero, por banalização dos problemas ambientais, bem como por adesão incondicional ao industrialismo, ao cientificismo e à doutrina de segurança nacional, típica dos anos de Guerra Fria (Lytle, 2007; Hecht, 2012; Souder, 2012; Musil, 2014).

No campo da política, a discussão acerca do uso dos pesticidas foi levada ao Parlamento e, oito anos após a publicação de Silent Spring, a Environmental Protection Agency - EPA decidiu erradicar o DDT em território estadunidense. Aos poucos, essa medida foi seguida por agências ambientais de diversos países do globo. No Brasil, a proibição ocorreu somente em 1985 (Flores et al., 2004). Para além da discussão acerca do uso dos pesticidas, Silent Spring também abriu portas para a consagração dos princípios da prevenção, da pre- caução, da informação, da participação popular e do poluidor-pagador, atualmente vigentes nas normas nacionais e internacionais de Direito Ambiental (Meiners et al., 2012).

Hetch (2012) observou que as críticas a Carson variaram ao longo dos anos. Enquanto os primeiros críticos se incomodavam com as implicações que Silent Spring poderia acarretar nos pressupostos e instituições científicas, seus sucessores focaram nas repercussões das ideias contidas no livro para a limitação do livre-mercado.

Os primeiros críticos de Silent Spring advogavam que o DDT consistia em uma tecnologia desenvolvida para o bem-estar e para o conforto humanos e se queixavam de que os argumentos de Carson se opunham, ao fim e ao cabo, ao desenvolvimento e ao progresso. Dentre esses críticos, Hetch (2012) destaca Robert White-Stevens, Edwin Diamond e Frederick J. Stare.

White-Stevens, bioquímico e diretor-assistente da divisão de pesquisas agronômicas da American Cyanamid, foi um dos primeiros e mais duros adversários de Carson. Era um explícito defensor dos pressupostos do cientificismo e do antropocentrismo ético. $\mathrm{O}$ autor defendia que os seres humanos haviam conquistado um status singular ao longo do processo evolutivo, conquista essa que lhes facultava manipular e controlar a natureza como melhor lhes conviesse. Em entrevista transmitida pela rede estadunidense de TV, CBS, White-Stevens argumentou que "equilíbrio natural" era um pressuposto místico (e não científico) assumido por Carson. Alertou, também, que se seguissem os ensinamentos da autora de Silent Spring, os homens estariam condenados a uma era de escuridão controlada por pragas, insetos e vermes (Lytle, 2007). 
Edwin Diamond (1963), por sua vez, na crítica a Silent Spring publicada no Saturday Evening Post em 28 de setembro de 1963, chegou a desferir ataques pessoais contra Rachel Carson. Afirmou que os argumentos de "Miss Carson" - uma forma de ressaltar ao grande público que se tratava de uma mulher solteira - eram mais emocionais do que científicos e que continham elementos de paranoia. Acusou-a de distorcer informações e de publicar meias-verdades propagando, assim, o alarmismo por meio de uma bela prosa e de estratégias sensacionalistas. Acusou-a, ainda, de defender um retorno a uma era sombria dominada por pragas e epidemias, para o benefício da vida de aves e de gatos.

Stare, nutricionista de Harvard, comparou a fartura e a saúde das sociedades que dispunham dos pesticidas com a carestia e a doença das que não dispunham. Qualificou os argumentos de Carson como irracionais e emotivos, na mesma linha de Diamond (Hetch, 2012).

Contemporaneamente, a autora vem sendo acusada, em um sítio da Internet ${ }^{6}$, de ter ceifado a vida de milhares de crianças africanas vitimadas pela malária, doença que supostamente poderia ter sido erradicada pelo uso do DDT (Lytle, 2007). A acusação, há pelo menos quatro anos vem sendo veiculada pelo Competitive Enterprise Institute, uma associação civil dedicada à defesa de políticas públicas que sustentem o livre mercado, a liberdade individual e a limitação dos poderes do Estado, isto é, das políticas públicas que propaguem a doutrina liberal.

Desse modo, Carson se tornou um símbolo retórico útil ao neoliberalismo: satanizando a autora de Silent Spring, os adeptos do livre mercado provariam a falência da intervenção estatal, mesmo quando supostamente bem-intencionada e aparentemente bem-sucedida. Em consequência, os neoliberais poderiam desacreditar, como um todo, as intervenções do Poder Público na economia (Hetch, 2012), em especial aquelas demandadas por movimentos ambientalistas.

Lytle (2007) e Hetch (2012), por fim, asseveram que os críticos de Carson costumam salientar e mesmo exagerar os aspectos de Silent Spring que mais lhes interessam, chegando a deturpar os seus argumentos, de modo a tornar o texto mais facilmente suscetível à refutação. Trata-se da velha "falácia do espantalho", ou seja, da deturpação de um argumento que se pretende criticar, com a finalidade de tornar a crítica mais fácil e mais atrativa aos leitores do que a teoria criticada.

Tanto Lytle (2007) quanto Hetch (2012) asseveram que tais críticos não considerariam, que Carson: 1) registrou óbice ao uso abusivo e desregrado dos pesticidas na agricultura, não a todo e qualquer uso de pesticidas; 2) salientava que não havia pesquisa científica suficiente acerca dos efeitos dos pesticidas no solo, nas águas, nos animais e nos homens, motivo que lhe levava a criticar o seu uso irrestrito; 3 ) não tratou do uso dos pesticidas no enfrentamento de doenças; 4) chamou atenção para o fato de que os parasitas da agricultura vinham se tornando progressivamente mais resistentes aos pesticidas, demandando quantidades cada vez maiores de veneno. Finalmente, para Hetch (2012), os críticos de Carson também desconsiderariam que: 5) Silent Spring é um livro de ecologia que ultrapassa

\footnotetext{
${ }^{6}$ Trata-se do sítio https://www.safechemicalpolicy.org/rachel-was-wrong, mantido pelo Competitive Enterprise Institute. Sítio acessado em $30 / 04 / 2019$, às $12: 12$ horas.
} 
as discussões sobre os efeitos dos pesticidas na saúde humana.

Longe de sepultar Rachel Carson e Silent Spring, as críticas que lhes foram dirigidas despertaram a curiosidade do grande público e trouxeram ainda mais publicidade para o debate, transformando a autora em uma celebridade (Lytle, 2007). Originalmente publicado em língua inglesa, Silent Spring foi traduzido para 30 idiomas, dentre os quais francês, alemão, espanhol, português, japonês, dinamarquês e sueco. A "controvérsia dos pesticidas" foi veiculada em publicações científicas, revistas, jornais e programas de televisão, atraindo a atenção de políticos, da comunidade científica, assim como dos cidadãos comuns. Por isso, olhando retrospectivamente, pode-se dizer que Carson cumpriu a missão a que se propôs (Meiners et al., 2012).

\section{Silent Spring, visto desde o século XXI}

Após mais de meio século desde a publicação de Silent Spring, restaram desautorizadas as acusações de "alarmismo" ou de "histeria", grosseiramente formuladas contra Rachel Carson pelos seus críticos. É que muitas das restrições de Rachel Carson aos agroquímicos organoclorados mantiveram a sua pertinência ao longo das últimas cinco décadas, após a realização de experimentos e testes, nas mais diversas disciplinas científicas. Pesquisas entomológicas, genéticas, geológicas, biomédicas, biológicas, químicas, bioquímicas, em saúde pública entre tantas outras disciplinas parecem confirmar que:

- as pragas agrícolas têm desenvolvido resistência a concentrações cada vez mais altas dos diferentes pesticidas. A resistência ao DDT, por exemplo, foi constatada em duas espécies de mosquito-Aedes tritaeniorhynchus e Aedes solicitans - já em 1946(Moreira et al.,2012).

- A depender de temperatura, acidez, umidade e quantidade de matéria orgânica, os organoclorados podem, sim, ficar retidos no ambiente por longos anos (Nunes \& Tajara, 1998; Yogi, 2002; Flores et al., 2004; Rissato et al., 2004; Alves et al., 2010).

- A ampla e contínua utilização de praguicidas provocou a contaminação de rios, lençóis freáticos e de oceanos, de modo que se pode constatar a presença de pesticidas sintéticos nos locais mais improváveis, tais como na neve que precipita no Alasca ou no gelo da Antártida (Yogi, 2002; Flores et al., 2004; Rissato et al., 2004).

- A contaminação dos cursos hídricos com pesticidas tem provocado dificuldades reprodutivas para determinadas espécies de peixe, tais como as trutas-do-mar (Flores et al., 2004).

- Em todo lugar, a fauna silvestre foi contaminada com pesticidas: desde os golfinhos da costa brasileira, até as águias-marinhas do Mar Báltico (Yogi, 2002; Flores et al., 2004).

- $\quad$ A ingestão de DDT enfraquece as cascas dos ovos das aves, o que, em todo o mundo, desde a década de 1980, tem reduzido drasticamente as populações de águias, falcões e açores (Flores et al., 2004). 
- Os compostos organoclorados estão, sim, presentes no leite humano, quer as mulheres pesquisadas residam em áreas agrícolas do Egito (Flores et al., 2004), quer residam em grandes aglomerados urbanos, tais como o Rio de Janeiro ou Cuiabá (Oliveira \& Dores, 1998; Mesquita, 2001).

- DDT e BHC foram encontrados em todas as amostras de tecido adiposo humano em uma pesquisa conduzida na Espanha. Por sua vez, em Uttar Pradesh e Bihar, regiões da Índia, todos os 60 indivíduos acometidos de câncer gastrintestinal estudados apresentavam altas concentrações biliares de BHC, DDT, Aldrin e Endosulfan (Flores et al., 2004).

- Apesar das grandes dificuldades inerentes à avaliação das contaminações crônicas, os pesticidas parecem mesmo estar associados a casos de câncer (em especial, de diferentes tipos de leucemia), a mutações celulares e a danos cerebrais (Nunes \& Tajara, 1998; Flores et al., 2004; Jobim et al., 2010).

\section{Conclus̃̃es}

Entre as décadas de 1940 a 1960, as indústrias químicas vendiam pesticidas sintéticos arguindo que, ao revés do que ocorria com os oitocentistas pesticidas à base de arsênico ("pesticidas naturais"), os seus novos produtos eram substâncias inofensivas aos seres humanos e a espécies mais complexas de organismos, tais como mamíferos, aves e peixes. Ao longo dos anos, essa alegação provou-se falsa. Pesticidas estão longe de poder ser caracterizados como substâncias inofensivas ao Homo sapiens. As pesquisas têm demonstrado que eles podem causar disfunções orgânicas crônicas em mamíferos, sem mencionar os incontáveis impactos ambientais de difícil previsão, controle, mensuração e reversão.

Por outro lado, os pesticidas desempenharam e ainda desempenham papel relevante no controle dos vetores de doenças tropicais, tais como a dengue, a malária, o mal de chagas e a leishmaniose. Ademais, dadas as condições climáticas favoráveis à difusão de insetos, dificilmente a produção agropecuária brasileira teria alcançado patamares promissores sem o uso desses agroquímicos.

Dito isso, como Rachel Carson e o seu Silent Spring podem contribuir para a "controvérsia dos pesticidas" no Brasil do século XXI? A começar, da mesma forma que o fizeram nos EUA do final do século XX: por meio da difusão e da democratização do debate a respeito da matéria.

Conforme apresentado neste artigo, o grande feito de Rachel Carson em Silent Spring não foi desenvolver pesquisas a respeito dos efeitos deletérios e indesejados dos pesticidas, até porque os seus argumentos centrais são construídos com dados secundários. O grande feito de Carson foi divulga-las, apresenta-las aos atores-chave da arena política e ao público leigo estadunidense em linguagem compreensível e prosa agradável. Desse modo, o cidadão estadunidense comum foi informado sobre o que estava em jogo. Isso lhe permitiu tomar parte das discussões e pressionar os agentes públicos, especialmente os que dependiam de votos.

É verdade que, diversamente do que ocorre nos EUA, ao longo de sua história, o Brasil tem abraçado uma arraigada e insistente tradição autoritária que alija o povo das principais decisões nacionais. Como se trata de um traço cultural persistente, a 
tendência é que a repitamos na nossa "controvérsia dos pesticidas".

Não obstante, é bem outro o caminho escolhido pela nova ordem jurídica brasileira, fundada com a promulgação da Constituição Cidadã, em 1988. O constituinte optou por reconhecer informação, opinião e participação como condições inerentes ao exercício democrático da soberania popular. Nesse aspecto, tanto os conteúdos publicados, quanto os métodos adotados por Rachel Carson podem ajudar.

Em verdade, as advertências de Carson a respeito dos riscos do uso indiscriminado de pesticidas eram válidas em 1962 e, em boa medida, ainda o são em 2019. De outra banda, nunca o Brasil demandou tanto por intelectuais que se prontificassem a realizar divulgação científica para o público leigo. Nesse sentido, escrever, em língua portuguesa, sobre a vida, a obra e o legado de Rachel Carson é também inspirar.

\section{Referências}

Alves, M. I. R.; Antoniosi Filho, N. R.; Oliveira, L. G.; Furtado, S. T. de F. Avaliação da contaminação por pesticidas organoclorados em recursos hídricos do Estado de Goiás. Revista Brasileira de Recursos Hídricos, 15(1), 67-74, 2010. Disponível em: http://repositorio.bc.ufg.br/ bitstream/ri/14235/5/Artigo\%20-\%20Maria\%20Isabel $\% 20$ Ribeiro\%20Alves\%20-\%202010.pdf

Barros, F. de S. O manifesto Russell-Einstein e as Conferências Pugwash. Física na escola, 6(1), 15-22, 2005. Disponível em http://www.sbfisica.org.br/fne/Vol6/Num1/ pugwash.pdf?hc_location=ufi

Beyl, C. A. Rachel Carson, Silent Spring, and the environmental movement. Hort Technology, 2(2), 272-275, 1992. Disponível em https://journals.ashs.org/horttech/view/ journals/horttech/2/2/article-p272.pdf
Bonzi, R. S. Meio século de Primavera silenciosa: um livro que mudou o mundo. Desenvolvimento e Meio Ambiente, 28, 207-215, 2013.

Borges, L. de G.; Fröehlich, P. E. Talidomida - novas perspectivas para utilização como anti-inflamatório, imunossupressor e antiangiogênico. Revista da Associação Médica Brasileira, 49(1), 96-102, 2003. Disponível em: http://www. scielo.br/pdf/ramb/v49n1/15388

Bourdieu, P. O campo científico. In: Ortiz, R. (Org.). Bourdieu, P. Sociologia. São Paulo: Ática. Coleção Grandes Cientistas Sociais, 39, 122-155, 1983.

Brasil. Lei $n^{\circ} 6.938$, de 31 de agosto de 1981. Dispõe sobre a Política Nacional do Meio Ambiente, seus fins e mecanismos de formulação e aplicação, e dá outras providências. Brasília/DF: DOU de 02/09/1981. Disponível em: http:// www.planalto.gov.br/ccivil_03/LEIS/L6938.htm

Brasil. Constituição da República Federativa do Brasil, de 5 de outubro de 1988. Brasília/DF: DOU de 05/10/1988. Disponível em: http://www.planalto.gov.br/ccivil_03/Constituicao/Constituicao.htm

Brasil. Lei $n^{\circ}$ 9.985, de 18 de julho de 2000. Regulamenta o art. 225, $\S 1^{\circ}$, incisos I, II, III e VII da Constituição Federal, institui o Sistema Nacional de Unidades de Conservação da Natureza e dá outras providências. Brasília/DF: DOU de 19/07/2000. Disponível em: http://www.planalto.gov. br/ccivil_03/leis/19985.htm

Brasil. Senado Federal. Projeto de Lei PL n. 6.299/2002. Altera os arts $3^{\circ}$ e $9^{\circ}$ da Lei $n^{\circ} 7.802$, de 11 de julho de 1989 , que dispõe sobre a pesquisa, a experimentação, a produção, a embalagem e rotulagem, o transporte, o armazenamento, a comercialização, a propaganda comercial, a utilização, a importação, a exportação, o destino final dos resíduos e embalagens, o registro, a classificação, o controle, a inspeção e a fiscalização de agrotóxicos, seus componentes e afins, e dá outras providências. Disponível em: $<$ https:// www.camara.leg.br/proposicoesWeb/prop_mostrarintegra;jsessionid=34818AAFA2DF6BA2DA56CFD16970F924. proposicoesWebExterno1?codteor $=1654426 \&$ filename $=-$ Tramitacao-PL+6299/2002>. Acesso em: jun. 2019.

Carson, R. The edge of the sea. Boston: Houghton Mifflin Company, 1955. 
Carson, R. O mar que nos cerca. São Paulo: Companhia Editora Nacional, 1956.

Carson, R. Silent Spring. 40 ed., Boston: Houghton Mifflin, 1962.

Carson, R. Beira-mar. São Paulo: Editora Gaia, 2010a.

Carson, R. Primavera silenciosa. $1^{\mathrm{a}}$ ed., São Paulo: Editora Gaia, 2010b.

Carson, R. Sob o mar vento. São Paulo: Gaia, 2011.

Davidson, C. I. Air Pollution In: Pittsburgh: A Historical Perspective. Journal of the Air Pollution Control Association, 29(10), 1035-1041, 1979. doi: $10.1080 / 00022470.1979 .10470892$

Davis, F. R. From the sea to Silent Spring. Science, 339(6123), 1034, 2013.

Diamond, E. The myth of the pesticide menace. Saturday Evening Post, 16-18, 1963. Disponível em: http://shipseducation.net/pesticides/library/diamond1963.pdf

Emico, O. As bombas atômicas podem dizimar a humanidade - Hiroshima e Nagasaki, há 70 anos. Estudos Avançados, 29(84), 209-218, 2015. doi: 10.1590/S010340142015000200014

Flores, A. V.; Ribeiro, J. N.; Neves, A. A.; Queiroz, E. L. R. de. Organoclorados: um problema de saúde pública. Ambiente \& Sociedade, VII(2), 111-124, 2004. doi: 10.1590/ S1414-753X2004000200007

Fundação Oswaldo Cruz - Fiocruz. Nota Técnica: Análise do Projeto de Lei n. 6.299/2002, 2018. Disponível em https://portal.fiocruz.br/sites/portal.fiocruz.br/files/documentos/nota_tecnica_pl_agratoxicos.pdf

Garnham, C. DDT versus malaria: a successful experiment in malaria control by the Kenya Medical Department [filmevídeo]. Produção East Africa Sound Studios, 1946. Disponível em https://wellcomelibrary.org/item/b16779150\#?$\mathrm{c}=0 \& \mathrm{~m}=0 \& \mathrm{~s}=0 \& \mathrm{cv}=0$. Acesso em: abr. 2019. 23 minutos e 02 segundos. Preto e branco. Som.

Giddens, A. The politics of climate change. Cambridge/ UK: Polity, 2009.

Gunter, V. J.; Harris, C. K. Noisy winter: the DDT contro- versy in the years before Silent Spring. Rural Sociology, 63(2), 179-198, 1998.

Hardin, G. The Tragedy of the Commons. Science, 162(3859), 1243-1248, 1968. Disponível em http://science. sciencemag.org/content/sci/162/3859/1243.full.pdf

Hecht, D. K. How to make a villain: Rachel Carson and the politics of antienvironmentalism. Revista Endeavour, 36(4), 149-155, 2012.

Hobsbawm, E. J. A era dos extremos: o breve século XX - 1914 a 1991. São Paulo: Companhia das Letras, 1995.

Jobim, P. F. C.; Nunes, L. N.; Giuliani, R.; Cruz, I. B. M. da. Existe uma associação entre mortalidade por câncer e uso de agrotóxicos?: Uma contribuição ao debate. Ciência \& Saúde Coletiva, 15, 277-288, 2010. Disponível em https:// www.scielosp.org/pdf/csc/2010.v15n1/277-288/pt

Lear, L. J. Rachel Carson's Silent Spring. Environmental History Review, 17(2), 23-48, 1993.

Lytle, M. H. The Gentle Subversive: Rachel Carson, Silent Spring and the Rise of the Environmental Movement. New York: Oxford University Press, 2007.

Machado, P. A. L. Princípios gerais de direito ambiental internacional e a política ambiental brasileira. Palestra pronunciada na XIV Conferência Nacional da OAB - Ordem dos Advogados do Brasil, Vitória/ES, nov. 1992. Revista de informação legislativa, 30(118), 207-218, 1993.

McCormick, J. Rumo ao Paraíso: a história do movimento ambientalista. Rio de Janeiro: Editora Relume-Dumará, 1992.

Meiners, R.; Desrochers, P.; Morriss, A. (Orgs.). Silent Spring at 50: The false crises of Rachel Carson. Cato Institute, Washingon, DC: 2012.

Mesquita, S. A. Avaliação da contaminação do leite materno por pesticidas organoclorados persistentes em mulheres doadoras do Banco de Leite do Instituto Fernandes Figueira, RJ. Rio de Janeiro (Mestrado em Saúde Pública), Fundação Oswaldo Cruz - ENSP/FIOCRUZ, 2001. Disponível em: https://www.arca.fiocruz.br/handle/icict/4938 Moreira, M. F.; Mansur, J. F.; Mansur-Figueira, J. Resistência e inseticidas: estratégias, desafios e perspectivas 
no controle de insetos. Instituto Nacional de Ciência e Tecnologia em Entomologia Molecular - INCT-EM, 15, 1-23, 2012. Disponível em http://www.inctem.bioqmed. ufrj.br/images/documentos/biblioteca/Capitulo_15_Resistencia_a_Inseticidas_-_Estrategias_Desafios_e_Perspectivas_no_Controle_de_-_nsetos.pdf

Musil, R. K. Rachel Carson and her sisters: extraordinary women who have shaped America's environment. London: Rutgers University, 2014.

Nunes, M. V.; Tajara, E. H. Efeitos tardios dos praguicidas organoclorados no homem. Revista de Saúde Pública, 32(4), 372-383, 1998. doi: 10.1590/S0034-89101998000400011

Oliveira, M. A. G. de; Dores, E. F. G. de C. Níveis de praguicidas organoclorados no leite materno de uma população de Cuiabá - Mato Grosso. Pesticidas: Revista de Ecotoxicologia e Meio Ambiente, 8, 77-90, 1998. Disponível em https://revistas.ufpr.br/pesticidas/article/view/39517/24292

Prost, A.; Vincent, G. (Orgs). História da vida privada, 5: da Primeira Guerra a nossos dias. Coleção dirigida por Philippe Ariès e Georges Duby. São Paulo: Companhia das Letras, 1992.
Quaratiello, A. R. Rachel Carson: a Biography.Connecticut: Greenwood Publishing Group, 2004.

Rissato, S. R.; Libânio, M.; Giafferis, G. P.; Gerenutti, M. Determinação de pesticidas organoclorados em água de manancial, água potável e solo na região de Bauru (SP). Química Nova, 27(5), 739-743, 2004. Disponível em https://www.scielo.br/scielo.php?pi$\mathrm{d}=$ S0100-40422004000500012\&script $=$ sci_abstract\&tl$\mathrm{ng}=\mathrm{pt}$

Saldanha, P. H. Tragédia da talidomida e o advento da teratologia experimental. Revista Brasileira de Genética = Brazilian Journal of Genetics, 17(4), 449-464, 1994.

Souder, W. On a Farther Shore: The life and legacy of Rachel Carson. Crown Publishers, New York, 2012.

Yogi, G. T. Ocorrência de compostos organoclorados (pesticidas e PCBs) em mamíferos marinhos da costa de São Paulo (Brasil) e da Ilha Rei George (Antártica). São Paulo (Mestrado em Oceanografia Química e Geológica) - USP, 2002. Disponível em https://www.teses.usp.br/teses/disponiveis/21/21133/tde-17032002-115002/pt-br.php 